\title{
Variation in Content and Function of Non-Neuronal Cells in the Outgrowth of Sympathetic Ganglia from Embryos of Differing Age
}

\author{
D. Roufa, ${ }^{1}$ M. B. Bunge, M. I. Johnson, ${ }^{\star}$ and C. J. Cornbrooks ${ }^{2}$ \\ Department of Anatomy and Neurobiology and *Departments of Pediatrics and Neurology, \\ Washington University School of Medicine, St. Louis, Missouri 63110
}

Studies on cellular interactions in the developing nervous system are greatly facilitated by the availability of tissue culture preparations that contain single or combined populations of neurons and non-neuronal cells (NNCs). Using superior cervical ganglia (SCG) from early E15 rats on air-dried collagen, we were able to prepare (1) cultures containing neurons along with Schwann cells (SCs) as the only NNC type present without the use of antimitotic treatment and (2) cultures containing only neurons, following brief antimitotic treatment. Light-microscopic observation of E15 outgrowth showed a uniform population of flattened cells, unlike that of E20 cultures, which contained a mixture of spindle-shaped and flattened cells. Autoradiograms following $\left[{ }^{3} \mathrm{H}\right]$ thymidine administration to $\mathbf{E} 15$ cultures revealed a striking gradient of nuclear labeling: Only a few cells were labeled near the explant and nearly all cells were labeled at the growth front. This was in marked contrast to E20 cultures, in which nuclei were labeled throughout the outgrowth. The conclusion that the labeling gradient is explained by the presence of SCs without other NNC types in E15 cultures was confirmed by immunocytochemical studies. Anti-laminin antibodies stain only those extracellular matrix components related to the SC surface, whereas anti-fibronectin antibodies stain fibroblast-related components (Cornbrooks et al., 1983a). Anti-laminin antibodies stained cell surfaces in both E15 and E20 outgrowth. E15 outgrowth did not stain with anti-fibronectin antibodies although marked staining was obtained in E20 cultures. Electron microscopy confirmed the presence of only SCs in E15, and of both SCs and fibroblasts in E20 outgrowth. Thus, it appears that there is a narrow developmental window in which the ganglia contain neurons and SCs but relatively few fibroblast components; cultures prepared from ganglia at this stage form outgrowth containing only neurites and SCs without antimitotic treatment. Surprisingly, neither SC ensheathment nor SC basal lamina formation was normal in E15 and E20 outgrowth. When either E15 or E20 SCG SCs were transplanted onto dorsal root ganglion neurons free of endogenous SCs, however, the sensory

Received Mar. 26, 1985; revised June 18, 1985; accepted June 20, 1985.

We are grateful for the technical assistance of Artree James, Stephen Rapp, and Ann Williams; gifts of antibodies from Drs. John McDonald (Department of Internal Medicine, Jewish Hospital, St. Louis, MO) and Rupert Timpl (MaxPlanck Institut für Biochemie, Federal Republic of Germany); fruitful discussions with Drs. Richard Bunge and Patrick Wood; the photographic assistance of Bob Freund; and the secretarial support of Susan Mantia. This work was supported by NIH Program Project Grant NS 15070 (M.B.B.), NIH NS 14416 (M.I.J.), and NIH NS 09923 (Richard P. Bunge).

Correspondence should be addressed to Dr. Bunge, Department of Anatomy and Neurobiology, Washington University School of Medicine, 660 South Euclid Avenue, St. Louis, MO 63110.

Present address: Health Care Division, Monsanto Company, 800 North Lindbergh Blvd., St. Louis, MO 63167.

${ }_{2}^{2}$ Present address: Department of Anatomy and Neurobiology, University of Vermont College of Medicine, Given Building, Burlington, VT 05405.

Copyright (C) 1986 Society for Neuroscience $0270-6474 / 86 / 030790-13 \$ 02.00 / 0$ neurites were typically ensheathed or myelinated and basal lamina appeared 9 d later, identifying the SCG NNCs as functionally competent SCs. The dramatically improved function of SCs relating to sensory axons suggests that these neurons have a more direct influence on SC function than do autonomic neurons; $\mathrm{SCs}$ accompanying autonomic neurons may be more influenced by nonaxonal environmental conditions, which, in the culture dish, include the presence of substratum and medium components. In summary, early E15 SCG cultures provide not only a highly convenient source of populations of neurons or neurons plus SCs (without fibroblasts) but also, along with E20 cultures, offer an opportunity to further study factors required for SC differentiation.

Cellular interactions between neurons and non-neuronal cells (NNCs) and their interactions with the extracellular matrix play a critical role in the development and organization of nervous tissuc (Aguayo and Bray, 1984; Bunge and Bunge, 1984; Bungc et al., 1983; Sanes, 1983; Varon and Bunge, 1978; Webster and Favilla, 1984). In vitro studies allow examination of the relative contributions of each cell type or component, independent of other factors, to neuronal and Schwann cell (SC) differentiation. An important tool for such studies is the array of tissue culture systems that provide pure populations of neurons, SCs or fibroblasts, or combinations of any of these (Brockes et al., 1979; Bunge et al., 1983; Manthorpe et al., 1980; McCarthy and Partlow, 1976; Wood, 1976). The effectiveness of using such tissue culture preparations to study cellular interactions is exemplified by the discovery and study of a mitogen for SCs on the sensory neurite surface (Salzer and Bunge, 1980; Salzer et al., 1980a, b; Wood, 1976; Wood and Bunge, 1975) and by the discovery and study of the interrelationship between ensheathment function and basal lamina formation by SCs (Bunge et al., 1983, and in press). Also, by culturing pure cell populations from normal and abnormal sensory ganglia, Cornbrooks et al. (1983b) were able to show that the deficient extracellular matrix formation in dystrophic mouse peripheral nervous tissue is related to abnormal SC function. We report here that, by culturing certain-age superior cervical ganglion (SCG) ganglion on airdried collagen, neuron-SC cultures may be obtained without antimitotic treatment and neuronal populations may be prepared with only a brief antimitotic regimen.

In our previous study (Roufa et al., 1983), we examined outgrowth of SCG harvested from embryonic (E15), perinatal (E20-21), and adult rats and grown on various types of substrata. When the substratal collagen was gelled by different methods or diluted before gelling by air drying, its three-dimensional configuration varied, as did the pattern of neuritic outgrowth, neuritic extension rate, and number of NNCs in the outgrowth. In addition, the outgrowth patterns varied with differences in ganglion age when the substratum was kept constant. For ex- 


\section{E15}

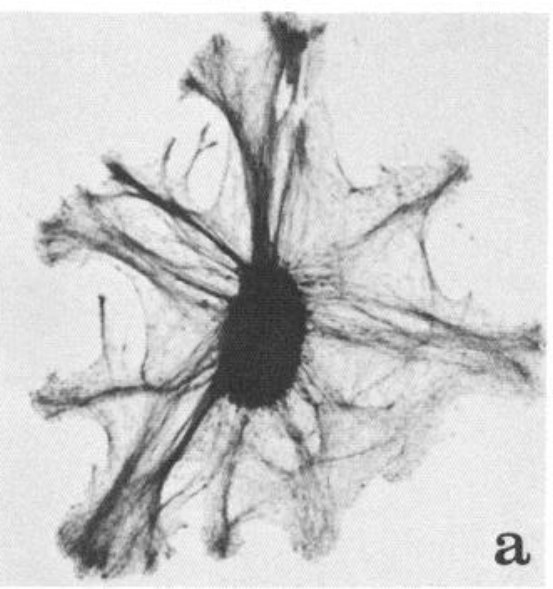

a

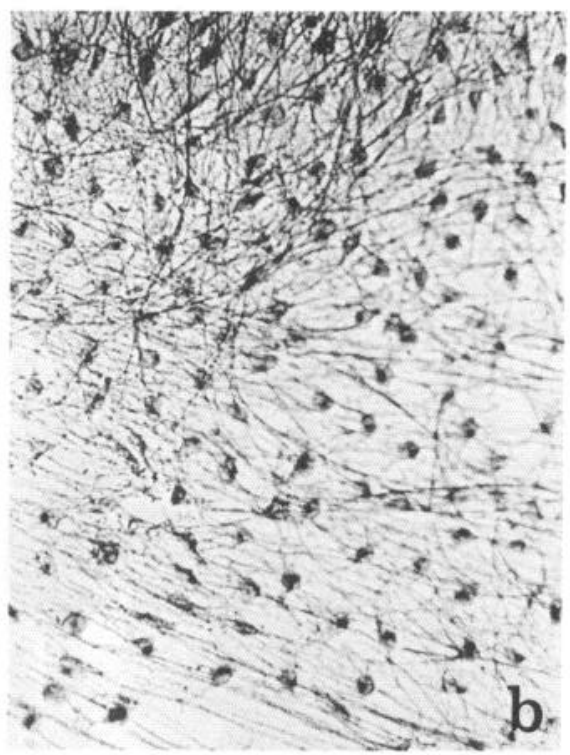

E20
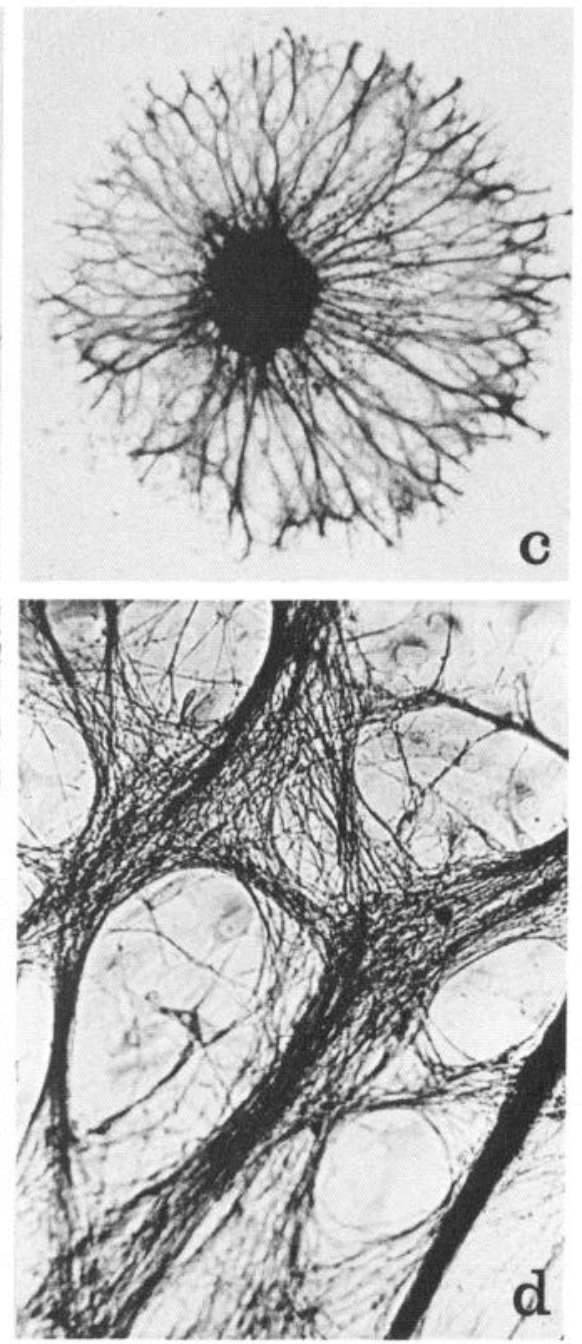

E15
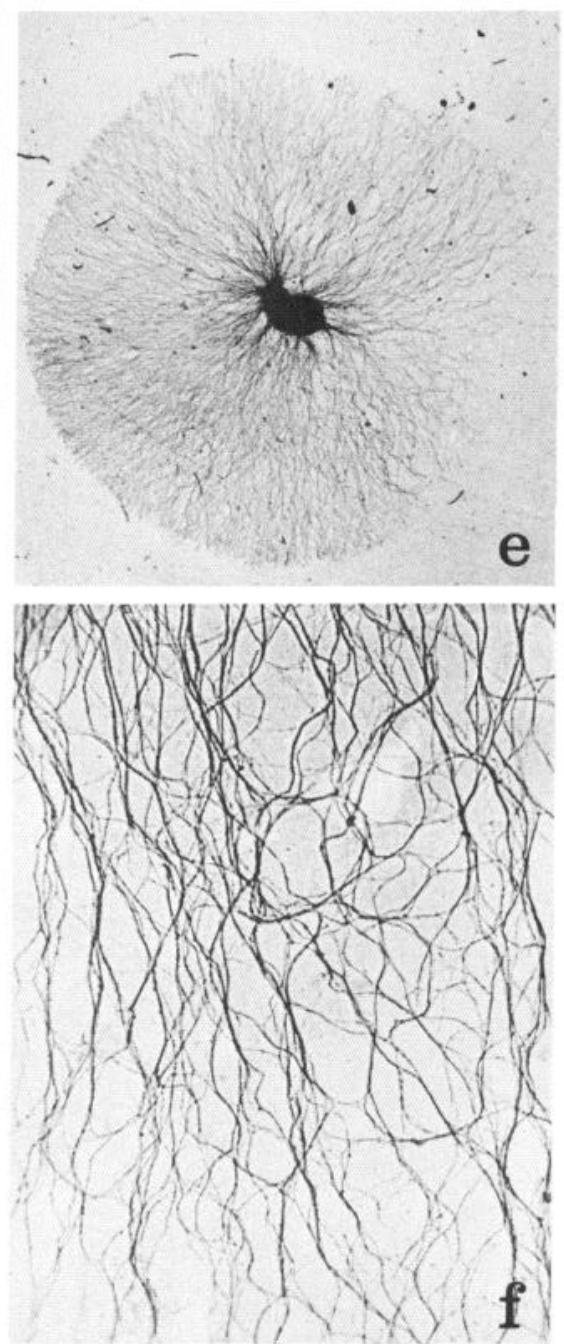

Figure 1. Characteristic morphology of outgrowth from E15 and E20 SCG explant cultures after $3 \mathrm{~d}$ in culture. SCG from E15 ( $a, b, e$, and $f)$ or E20 $(c, d)$ rats were plated on $16 \times$ diluted $(a-d)$ or undiluted $(e, f)$ air-dried collagen. Outgrowth of E15 explants contains flattened cells and a network of fine neurites ( $a$ and $b$ ). (In $b$, only the nuclei of the flattened cells are visible.) E20 outgrowth contains variously shaped NNCs, flattened polygonal cells, and spindle-shaped cells, which are aligned along the numerous fasciculated neurites $(c$ and $d)$. (The spindle-shaped cells are not seen well in $d$ because they are integrated into the neuritic fascicles.) E15 explants grown in the presence of fluorodeoxyuridine formed neuritic outgrowth devoid of all NNCs $(e$ and $f$ ). Sudan black staining. $a, c$, and $e, \times 10 . b, d$, and $f, \times 490$.

ample, when placed on diluted (two-dimensional) air-dried collagen, E20 SCG outgrowth was more fasciculated than E15 SCG outgrowth. We also noted that the population of NNCs appeared to differ in E15 and E20-21 SCG outgrowth; in early E15 cultures there appeared to be a uniform population of flattened cells that were closely related to neurites, whereas in E20-21 cultures there were both spindle-shaped cells related to neurites and flattened cells within and outside the territory of the neurites. It therefore became apparent that differences in neuritic outgrowth patterns as a function of ganglionic age reflected not only differences in neurons but also variation in type and behavior of the accompanying NNCs. Because the flattened NNCs in E15 outgrowth were thought to be SCs and the spindle-shaped and flattened NNCs in E20 outgrowth were thought to be SCs and fibroblasts, respectively, criteria other than cell shape were needed to identify these cell populations. The present report characterizes the NNCs that migrate out of early E15 and E20 SCG explants onto air-dried collagen by the following criteria: nuclear thymidine labeling patterns, immunocytochemical staining, results of a functional test to detect myelin formation by SCs, and electron-microscopic observations. A preliminary report of this study has been published (Roufa et al., 1982).

\section{Materials and Methods}

\section{Tissue culture}

All tissues were obtained from Holtzmann rat embryos. Pregnancies were accurately dated from the presence of sperm in a vaginal wash, noted as day 0 . Embryos were removed from pregnant rats under ether anesthesia. Accurate dating was critical because ganglia from early 15d-old embryos gave rise to a homogenous NNC population, in contrast to late E15 ganglia. When early E15 SCG were cultured, fibroblasts appeared along with SCs in only a small percentage of the cultures.

\section{Superior cervical ganglia}

SCG were grown in culture, essentially as described earlier (Roufa et al., 1983). They were removed from early $15-$ or 20 -d-old (E15 and E20) embryos: E20 SCG were carefully stripped of any connective tissue, using fine forceps. Such stripping of E15 SCG was not possible, as they have only poorly defined or no connective tissue capsule. The ganglia 


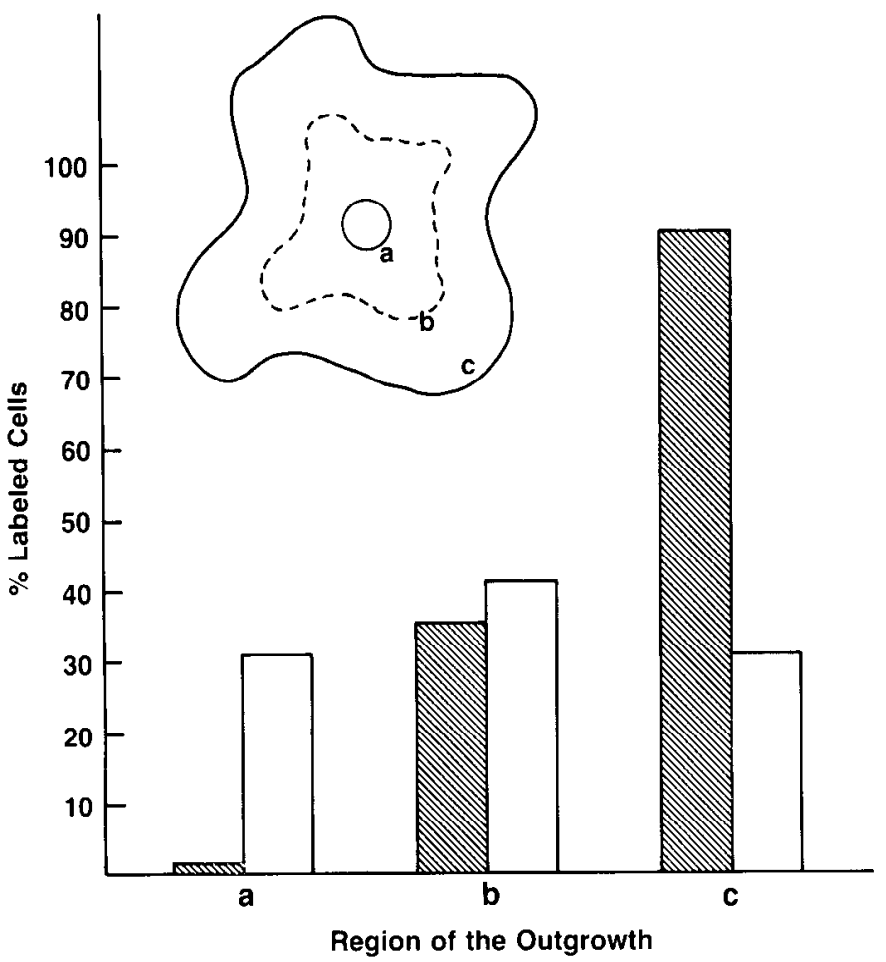

Figure 2. Extent of $\left[{ }^{3} \mathrm{H}\right]$ thymidine incorporation into nuclei of cells in the outgrowth of E15 vs E20 explant cultures. After 3 d in culture, SCG explants were incubated with $\left[{ }^{3} \mathrm{H}\right]$ thymidine for $24 \mathrm{hr}$, processed for autoradiography, and counterstained with toluidine blue (see Materials and Methods). Total number of cells and labeled cells was counted in five fields for each region of the outgrowth. $a$. Near the explant; $b$, midway between the explant and the growth front (although it was the front at the time of thymidine addition on day 3 ); $c$, at the outgrowth front. $\mathbb{E} 15 ; \square, \mathrm{E} 20$.

were plated on collagen substrata spread on $24 \mathrm{~mm}$ Aclar (33C, Allied Chemical Co.) dishes (Bunge and Wood, 1973). E15 SCG were approximately $1 \mathrm{~mm}$ long and thus were plated intact, whereas E20 SCG were cut into two or three pieces, approximately $1 \mathrm{~mm}$ long, prior to plating. All explants were plated with four or five drops of culture medium to promote their attachment, but, after $24 \mathrm{hr}$, additional medium was added to cover the explant; the culture medium was changed every other day thereafter. In one experiment, E15 SCG were also grown on a carpet of previously established skin fibroblasts harvested from 19 d rat embryos.

\section{Dorsal root ganglia}

Cultures containing pure populations of dorsal root ganglion neurons were prepared as described by Wood (1976; see also rcvicw by Eunge et al., 1983). Dorsal root ganglia were removed from 19 or $20 \mathrm{~d}$ rat embryos, decapsulated, dissociated with $0.25 \%$ trypsin (Worthington, $3 \times$ recrystallized) for $30 \mathrm{~min}$ at $35^{\circ} \mathrm{C}$, plated on a single (ammoniated) or double (see below) layer of collagen, and treated with antimitotic medium until the NNCs had been eliminated.

\section{Culture medium and substratum}

The standard culture medium contained $85 \%$ Eagle's minimum essential medium (GIBCO, Grand Island, NY), 10\% human placental serum, 2\% embryo extract, $0.6 \%$ glucose, $1 \%$ L-glutamine (GIBCO), and $10 \mathrm{BU} /$ $\mathrm{ml} 7 \mathrm{~S}$ NGF. The "antimitotic medium" contained the standard medium plus uridine and fluorodeoxyuridine (10 $\mu \mathrm{M}$ each). All cultures were maintained in a humidified atmosphere of $5 \% \mathrm{CO}_{2}$ in air at $35^{\circ} \mathrm{C}$. Collagen was extracted from rat-tail tendon with $0.1 \%$ acetic acid, using the protocol described by Roufa et al. (1983). The collagen stock solution $(5 \mathrm{mg} / \mathrm{ml})$ was diluted to the desired concentration (Roufa et al., 1983) and spread on culture dishes as a single or double layer. The single layer was gelled either by air drying or by $2 \mathrm{~min}$ exposure to $\mathrm{NH}_{3}$ vapor; in both cases the collagen was air-dried for $1 \mathrm{hr}$ and rewetted with Leibovitz's L-15 medium prior to use. In some experiments, sympathetic or dorsal root ganglia were grown on a double layer of undiluted collagen; the first layer was exposed to $\mathrm{NH}_{3}$ vapor for $2 \mathrm{~min}$, rinsed, and airdried; then, the second layer of collagen was spread and air-dried without ammoniation. (The double collagen layer was devised as a longer-lasting substratum for long-term maintenance of sympathetic ganglion cultures.)

\section{Light microscopy}

\section{Sudan black staining}

Sudan black staining was used as described by Roufa et al. (1983). Cultures were rinsed in Earle's balanced salt solution (GIBCO), fixed in $2 \%$ glutaraldehyde for $1-24 \mathrm{hr}$, postfixed in $2 \% \mathrm{OsO}_{4}$ in $0.1 \mathrm{M} \mathrm{PO}_{4}$ at $\mathrm{pH} 7.2$ for $1 \mathrm{hr}$ at $4^{\circ} \mathrm{C}$, rinsed, and dehydrated in a vertical position to $70 \%$ ethanol. The slides were then stained with $0.5 \%$ Sudan black in $70 \%$ ethanol for $90 \mathrm{~min}$, rehydrated, and mounted, tissue side down, in glycerin jelly.

\section{Immunocytochemical staining}

Staining with anti-fibronectin (from Dr. J. A. McDonald) or anti-laminin (from Dr. R. Timpl) antibodies was done as described by Cornbrooks et al. (1983a). Primary antibodies were diluted in a medium containing HEPES-buffered Dulbecco's modified Eagle's medium containing $10 \%$ heat-inactivated horse serum. Aclar dishes were cut into small pieces, with care taken not to disrupt the tissue, and incubated with $30-50 \mu \mathrm{l}$ of diluted primary antibodies for $1-3 \mathrm{hr}$ at $37^{\circ} \mathrm{C}$ in a humidified chamber. Cultures were rinsed in the diluting medium, as described above, and then incubated for $20 \mathrm{~min}$ at $4^{\circ} \mathrm{C}$ in the dark with the appropriate fluorescein-conjugated secondary antibody (Cappel Laboratories, Cochranville, PA). After rinsing, the cultures were fixed in $3 \%$ paraformaldehyde in PBS ( $\mathrm{pH} 7.2$ ) for $15 \mathrm{~min}$, rinsed, and then a drop of glycerol in PBS and phenylenediamine was added. The Aclar pieces were placed on glass slides, tissue side up, and a coverslip was placed on top of the tissue and secured with DPX (Gallard-Schlessinger, Carle Place, NY). Slides were viewed on a Zeiss Universal microscope, equipped with epifluorescence, with $16 \times$ and $40 \times$ oil-immersion objectives, and photographed with Kodak Tri-X film.

\section{Autoradiography}

Culturcs were labeled with $\left[{ }^{3} \mathrm{H}\right]$ thymidine $(1 \mu \mathrm{Ci} / \mathrm{ml})$ in standard culture medium for $24 \mathrm{hr}$, fixed, and dehydrated. The rims of the Aclar dishes were cut off so that cultures could be attached as a coverslip (tissue side up) to glass slides with DPX. The slides were dipped in Kodak NTB2 emulsion (diluted 1:1 with water), exposed for 1 week at $4^{\circ} \mathrm{C}$, developed, and stained for $1 \mathrm{~min}$ with $0.25 \%$ toluidine blue. Following staining, the cultures were dehydrated to $100 \%$ ethanol, rinsed in xylene, and covered with coverslips and DPX. Slides were viewed on a Zeiss Universal microscope and photographed with Kodak Panatomic X film.

\section{Electron microscopy}

E15 and E20 (or E21) cultures were prepared for electron-microscopic examination after $3,10,11,20$, or $30 \mathrm{~d}$ in vitro. Cultures were rinsed with Earle's balanced salt solution, fixed in $0.046 \mathrm{M}$ phosphate buffer (pH 7.2), 2\% glutaraldehyde, and 40-100 mm sucrose at room temperature for $10 \mathrm{~min}$ and at $4^{\circ} \mathrm{C}$ for $1 \mathrm{hr}$ or overnight. After rinsing, cultures were postfixed for $1 \mathrm{hr}$ at room temperature in $2 \% \mathrm{OsO}_{4}$ in $0.1 \mathrm{~m}$ phosphate buffer, dehydrated in ethanol, and embedded in Epon-Araldite. Outgrowth areas of interest (as assessed by phase microscopy) were sectioned perpendicular to the plane of the culture dish (to allow viewing transversely sectioned fascicles) using a Porter-Blum MT-2 ultramicrotome equipped with a diamond knife (Diatome). Sections were stained with uranyl acetate and lead citrate and examined in a Philips 300 EM.

\section{Results}

\section{General observations}

E15 and E20 SCG explants grown in vitro on a substratum of air-dried reconstituted rat-tail collagen exhibit an outgrowth morphology characteristic for each age group. After $3 \mathrm{~d}$ in vitro, E15 (Fig. $1 a$ ) and E20 (Fig. 1c) explants manifested similar outgrowth lengths when plated on $16 \times$ diluted $(0.2-0.3 \mathrm{mg} / \mathrm{ml})$ 


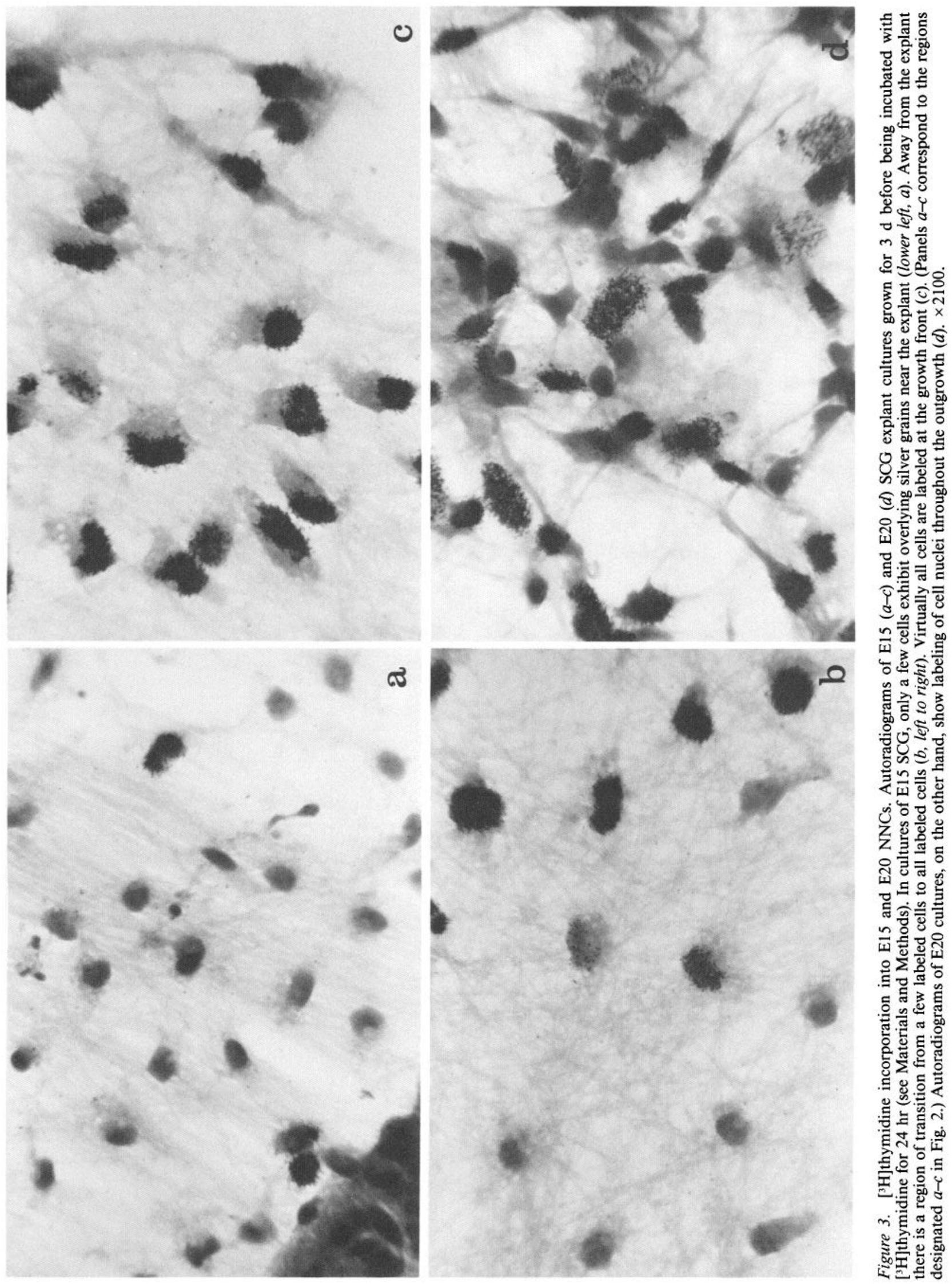




\section{E15}
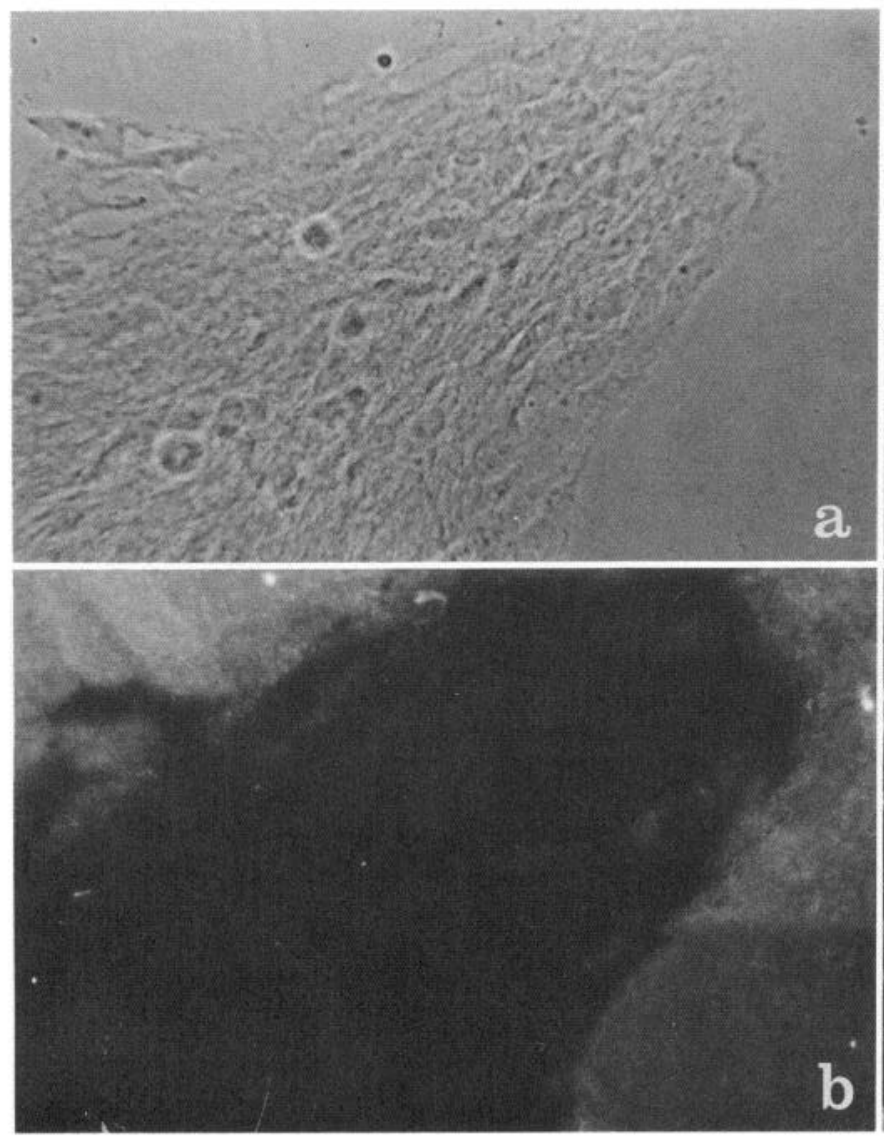

E20
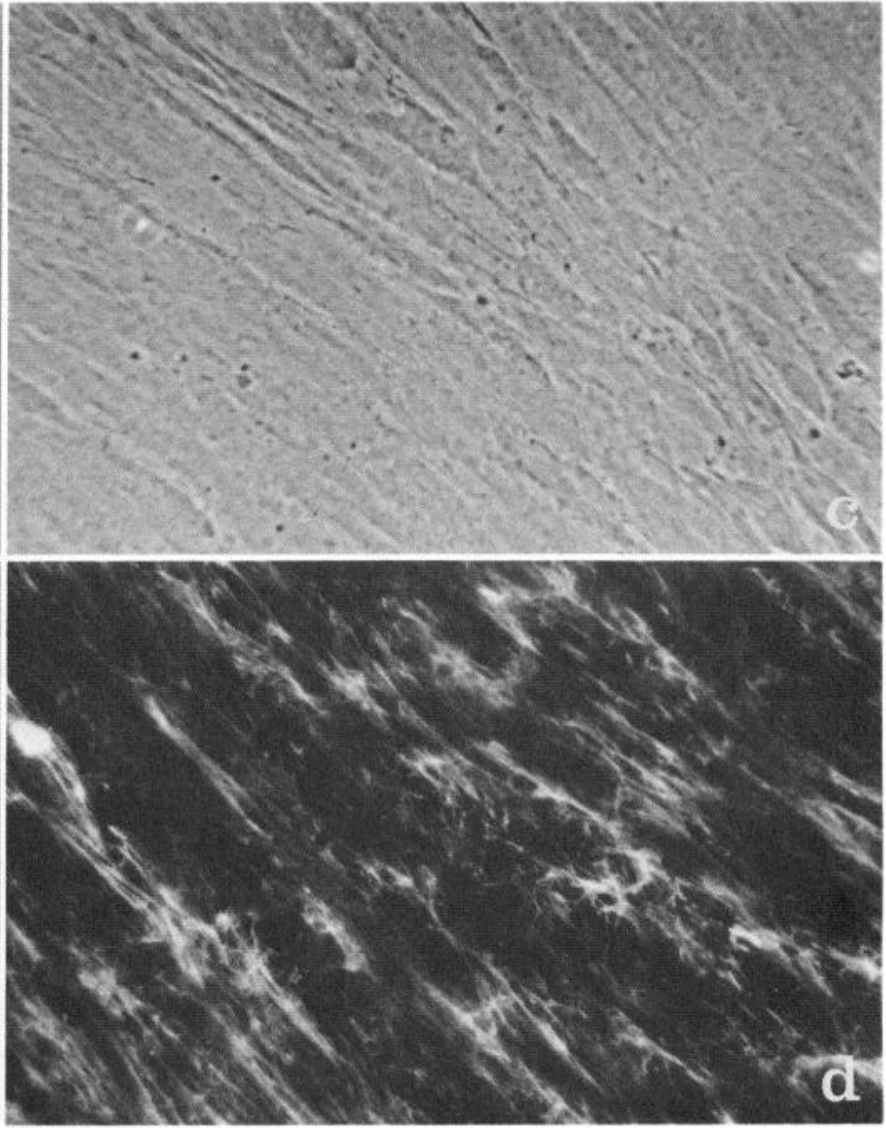

Figure 4. Immunocytochemical identification of NNCs with anti-fibronectin antibodies. Phase $(a$ and $c)$ and fluorescence $(b$ and $d)$ micrographs of E15 $(a$ and $b)$ and E20 ( $c$ and $d$ ) SCG outgrowth. No staining is seen within the E15 outgrowth $(b)$; the faint, diffuse staining outside the outgrowth region is due to adsorption of serum fibronectin to the acellular culture substratum. Anti-fibronectin antibody staining is observed throughout the E20 outgrowth $(d)$. Three days in vitro; $\times 490$.

air-dried collagen. Outgrowth length was not the same for E15 and E20 SCG, however, when grown on either a thicker collagen $(\sim 5 \mathrm{mg} / \mathrm{ml})$ or a more dilute collagen $(\sim 0.1 \mathrm{mg} / \mathrm{ml})$ substratum (Roufa et al., 1983). Under conditions allowing similar growth rates, E15 and E20 SCG outgrowth areas differed morphologically.

Outgrowth of E15 SCG explants (Fig. 1a) contained what appears to be a uniform population of flattened NNCs associated with a fine network of neurites (Fig. $1 b$ ). E20 outgrowth contained both flattened cells away from the neurites and spindleshaped cells aligned along fasciculated neuritic processes. Unlike E15 outgrowth, numerous neuritic fascicles were present in E20 outgrowth (Fig. 1, $b$ vs $d$ ).

NNCs migrating out of E15 explants proliferated rapidly and were thus very sensitive to the antimitotic agent utilized. After 2-3 d of growth in the presence of $10 \mu \mathrm{M}$ uridine and fluorodeoxyuridine in the culture medium, all NNCs were eliminated, yielding a preparation of SCG neurons alone (Fig. 1, $e$ and $f$ ). These cultures remained free of all NNCs for as long as 6 weeks, even though they were maintained in a medium without an antimitotic agent. More extensive antimitotic treatment is required to remove NNCs from E20 SCG (see Estridge and Bunge, 1978).

\section{Patterns of NNC thymidine labeling}

The sensitivity of E15 NNCs to fluorodeoxyuridine suggested a high rate of cell division. In order to identify the cells engaged in DNA synthesis, we labeled E15 and E20 explant cultures with $\left[{ }^{3} \mathrm{H}\right.$ ]thymidine $(1 \mu \mathrm{Ci} / \mathrm{ml})$ on day 3 for $24 \mathrm{hr}$ and processed these cultures for autoradiography, as described in Materials and Methods. A striking gradient of nuclear labeling was present in E15 cultures from the explant edge to the outgrowth front (Fig. 2, $a-c$ ). Near the explant rim (Figs. $2 a$ and $3 a$ ), $\sim 2 \%$ of the cells were labeled. Midway between the explant rim and the outgrowth front, $\sim 35 \%$ of the cells were labeled (Fig. $2 b$; see also Fig. $3 b$ ). The percentage of cells labeled changed gradually from very low (Fig. $3 b$, left) to very high (Fig. $3 b$, right). At the outgrowth front, $\sim 90 \%$ of the cells had incorporated $\left[{ }^{3} \mathrm{H}\right]$ thymidine into their nuclei (Figs. $2 c$ and $3 c$ ). We did not see this type of nuclear labeling gradient in E20 explant outgrowth; a similar percentage of labeled cells was present throughout the extent of the outgrowth (Figs. 2, $a-c$, and $3 d$ ). An increasing gradient of mitotic cells from explant rim to outgrowth front in E1 5 cultures is consistent with the presence of SCs only, because SCs alone require the presence of a mitogen on the axonal surface in order to proliferate (Salzer and Bunge, 1980; Salzer et al., 1980a, b; Wood and Bunge, 1975). As the outgrowth expands, the number of responding SCs typically diminishes near the explant (Salzer and Bunge, 1980); the explanation underlying this cessation of response to the mitogen is not yet known (Ratner, in press). Fibroblasts, which do not require the axonal mitogen for proliferation, divide throughout the entire outgrowth region in these cultures fed serum-containing medium. The uniform appearance of labeled NNC nuclei in E15 
E15
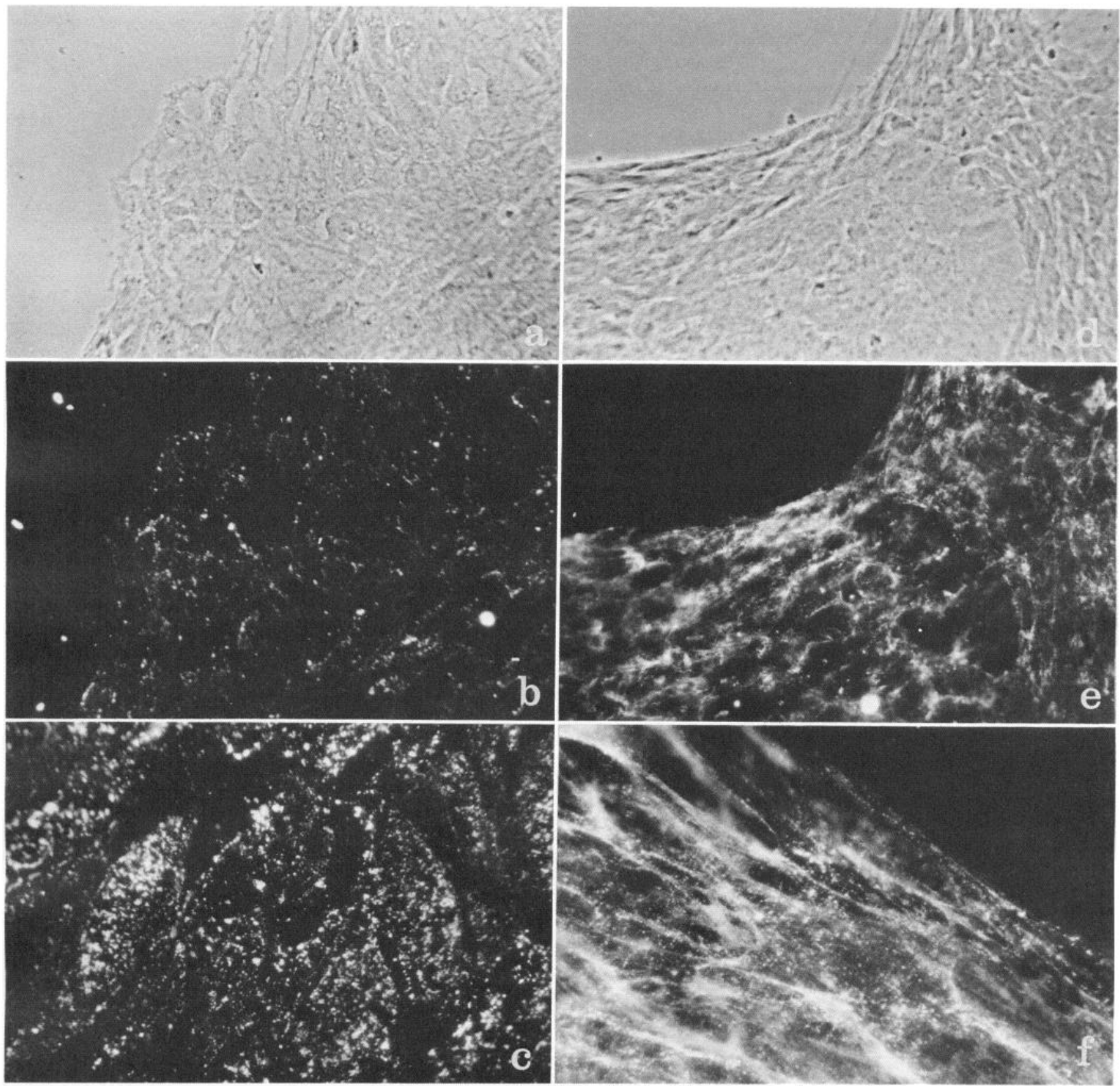

Figure 5. Immunocytochemical identification of NNCs with anti-laminin antibodies. Phase-contrast $(a, d)$ and fluorescence micrographs $(b, c, e$, and $f)$ of E15 $(a-c)$ and E20 $(d-f)$ SCG outgrowth. NNCs throughout the E15 outgrowth are stained $(b)$; at higher magnification, the staining pattern appears punctate and outlines the individual cells $(c)$. NNCs throughout the E20 outgrowth also are stained, but with a more complex pattern. Three days in vitro; $a, b, d$, and $e, \times 490 ; c$ and $f, \times 1225$.

cultures (e.g., Fig. $3 c$ ) versus the heterogeneous appearance (density of label and nuclear size) of the labeled nuclei in E20 cultures (Fig. 3d) also suggested that E15 outgrowth contained a homogenous population of NNCs, most likely SCs, whereas E20 cultures contained two or more NNC types, most likely SCs and fibroblast-like cells.

\section{Immunocytochemical identification of NNCs}

Cornbrooks et al. (1983a) found that affinity-purified antibodies raised against human plasma fibronectin stain only fibroblast- containing cultures, whereas affinity-purified anti-laminin antibodies bind to SCs but not to fibroblasts. We have used these two markers, therefore, to distinguish between SCs and fibroblasts in E15 and E20 SCG explant cultures.

E15 outgrowth did not stain with anti-fibronectin antibodies (Fig. 4, $a$ and $b$ ) whereas components of E20 outgrowth were heavily stained (Fig. 4, $c$ and d). The staining pattern of E20 outgrowth was fibrillar, characteristic of fibronectin staining on the cell surface and in the extracellular matrix. These results indicated that E20 cultures, in contrast to E15 preparations, contained fibroblasts. 

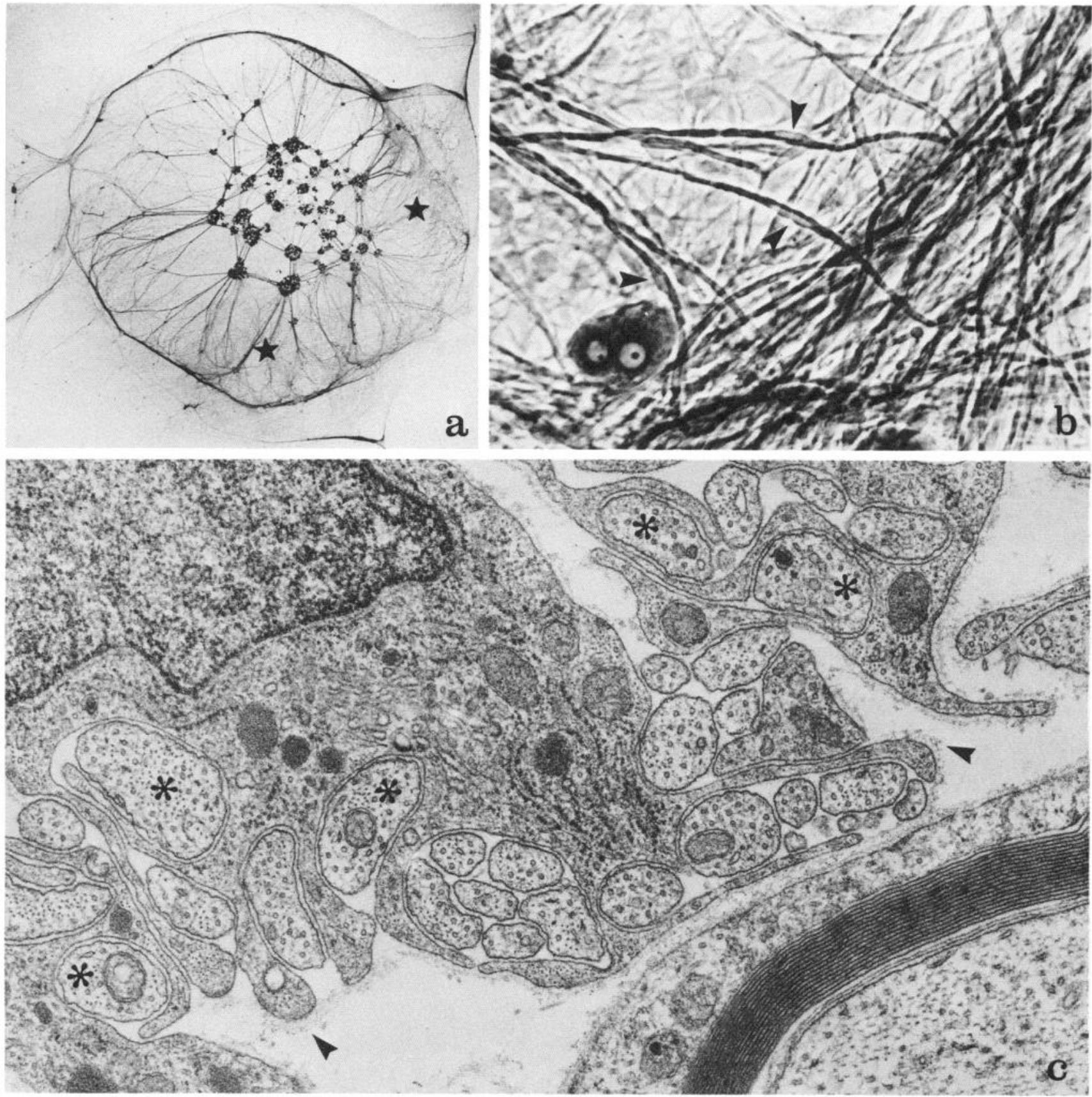

Figure 6. Myelination of sensory neurites by SCs from E15 sympathetic ganglion outgrowth. $a$, Low-power micrograph of Sudan black-stained dorsal root ganglion network to which E15 NNCs were added in areas marked with stars. $b$, Phase-contrast micrograph of the same dorsal root ganglion culture $9 \mathrm{~d}$ after the addition of E15 NNCs. Numerous myelin segments and their SC nuclei (at arrowheads) are evident. $c$, Electron micrograph of an area similar to that seen in $b$, showing the development of cytoplasmic ensheathment of unmyelinated neurites (asterisks) and the formation of myelin (lower-right corner) by E15 SCG SCs in the presence of sensory neurons for $9 \mathrm{~d}$. Accompanying the appearance of normal $\mathrm{SC}$ ensheathment function is the formation of extracellular matrix, basal lamina (arrowheads), and thin collagen fibrils. Ammoniated collagen substratum. $a, \times 10 ; b, \times 2100 ; c, \times 39,000$.

Figures 7 and 8. 7, Outgrowth from E20 ganglion after $10 \mathrm{~d}$ of culture. This electron micrograph shows the layering of fibroblasts, SCs, and neurites typically seen in the outgrowth of relatively young cultures of E20 SCG. Just above and parallel with the substratum (arrowhead), prepared from $20 \times$ diluted air-dried collagen, are the fibroblasts $(f b)$, which contain prominent cisterns of granular endoplasmic reticulum. SCs are situated above the fibroblasts; one is shown here. The SCs are not necessarily parallel to the substratum, as is also true of their endoplasmic reticulum cisterns. Beside and above the SCs are clusters of cross-sectioned neurites. There is neither ensheathment of neurites nor formation of extracellular matrix. $\times 23,000.8$, Outgrowth from E15 ganglion after $20 \mathrm{~d}$ of culture. Though surrounded by neurites, the SCs form only "meandering" processes (arrowheads) that do not accomplish ensheathment, as shown in this electron micrograph. Basal lamina is absent from the SC surface. This culture is a sibling of the one from which SCs were obtained (at this time in culture) to add to sensory neuron cultures (Fig. 6). Diluted (20x) air-dried collagen. $\times 41,000$. 


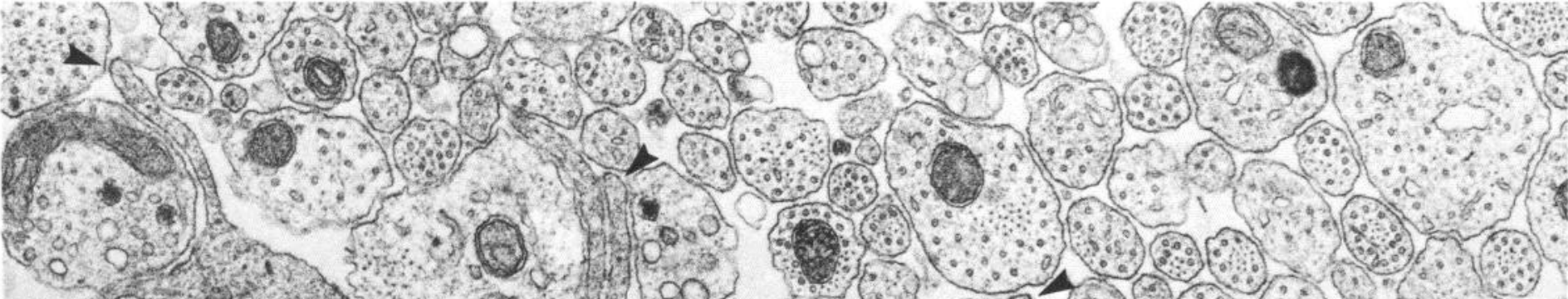
50 15)

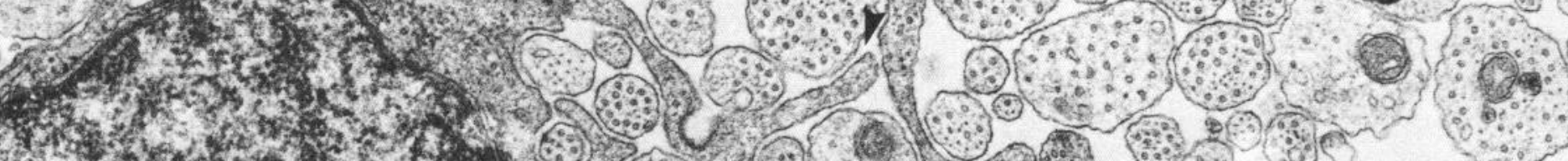

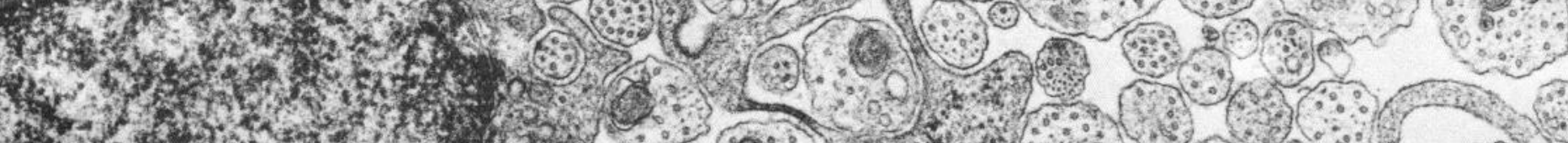
7.

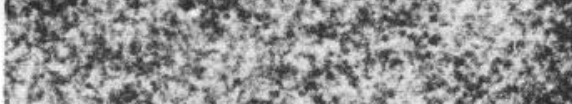
W.

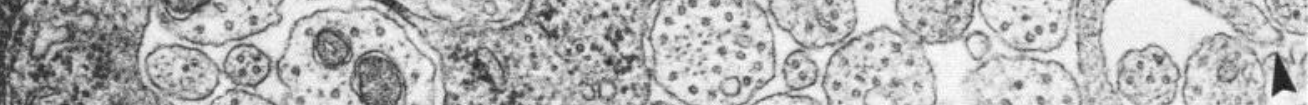

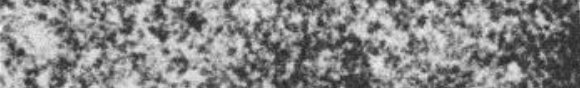

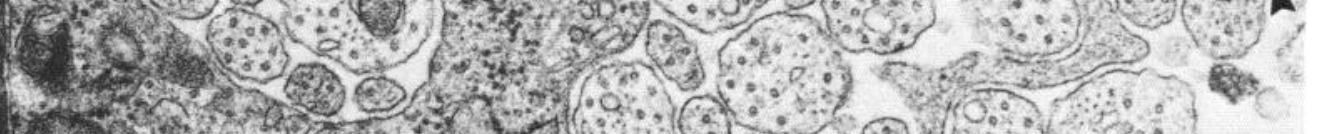
2.

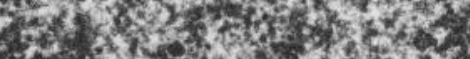

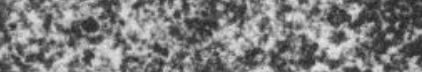

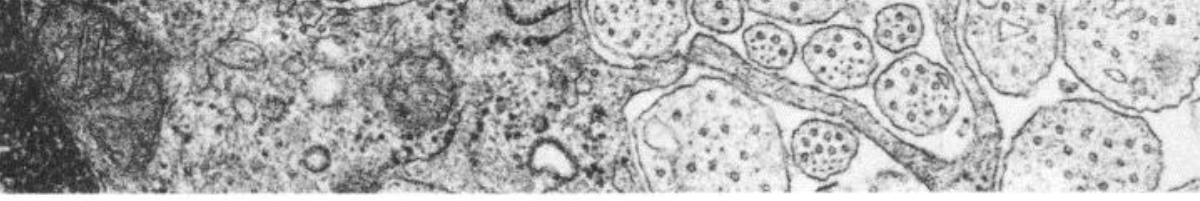

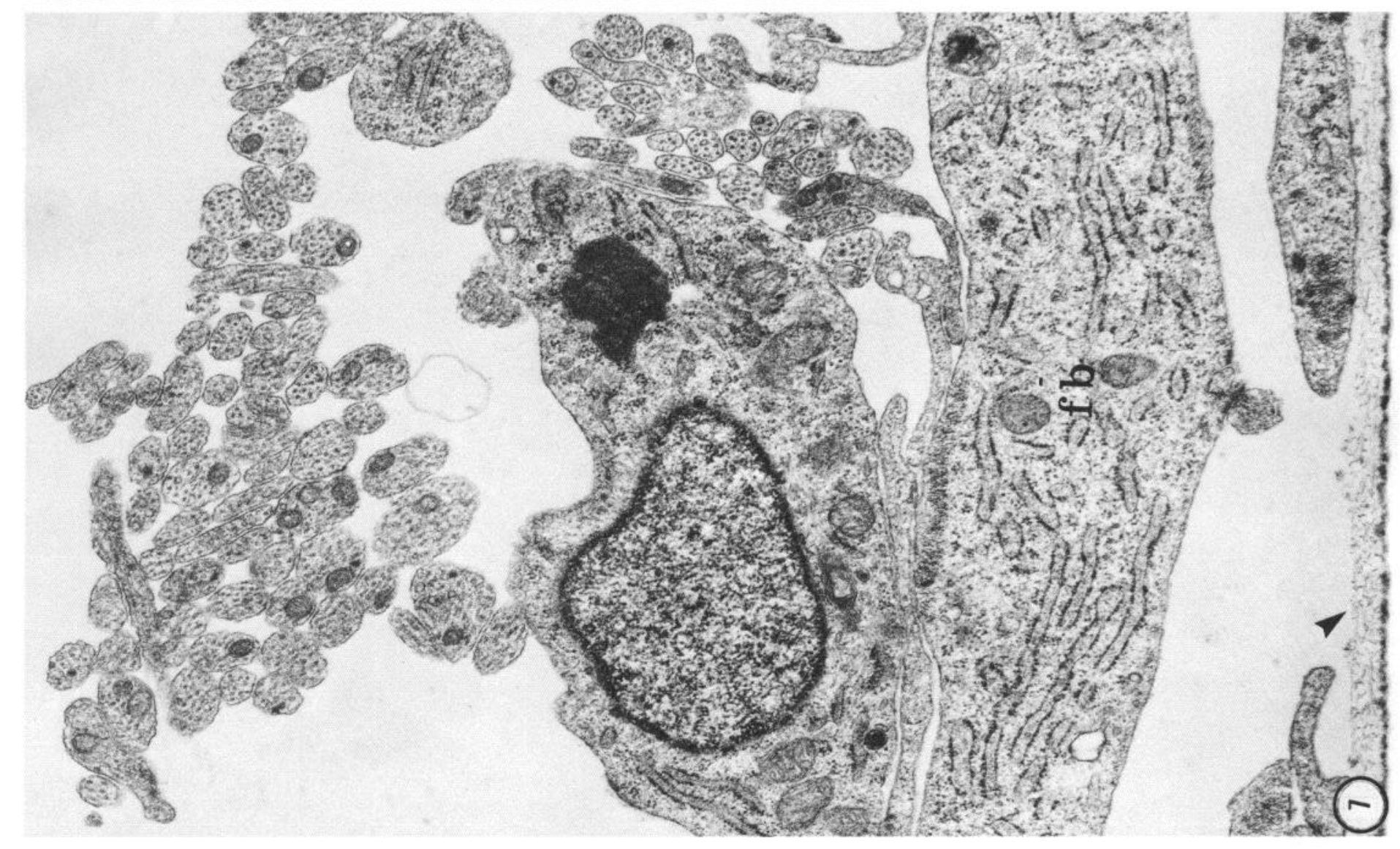




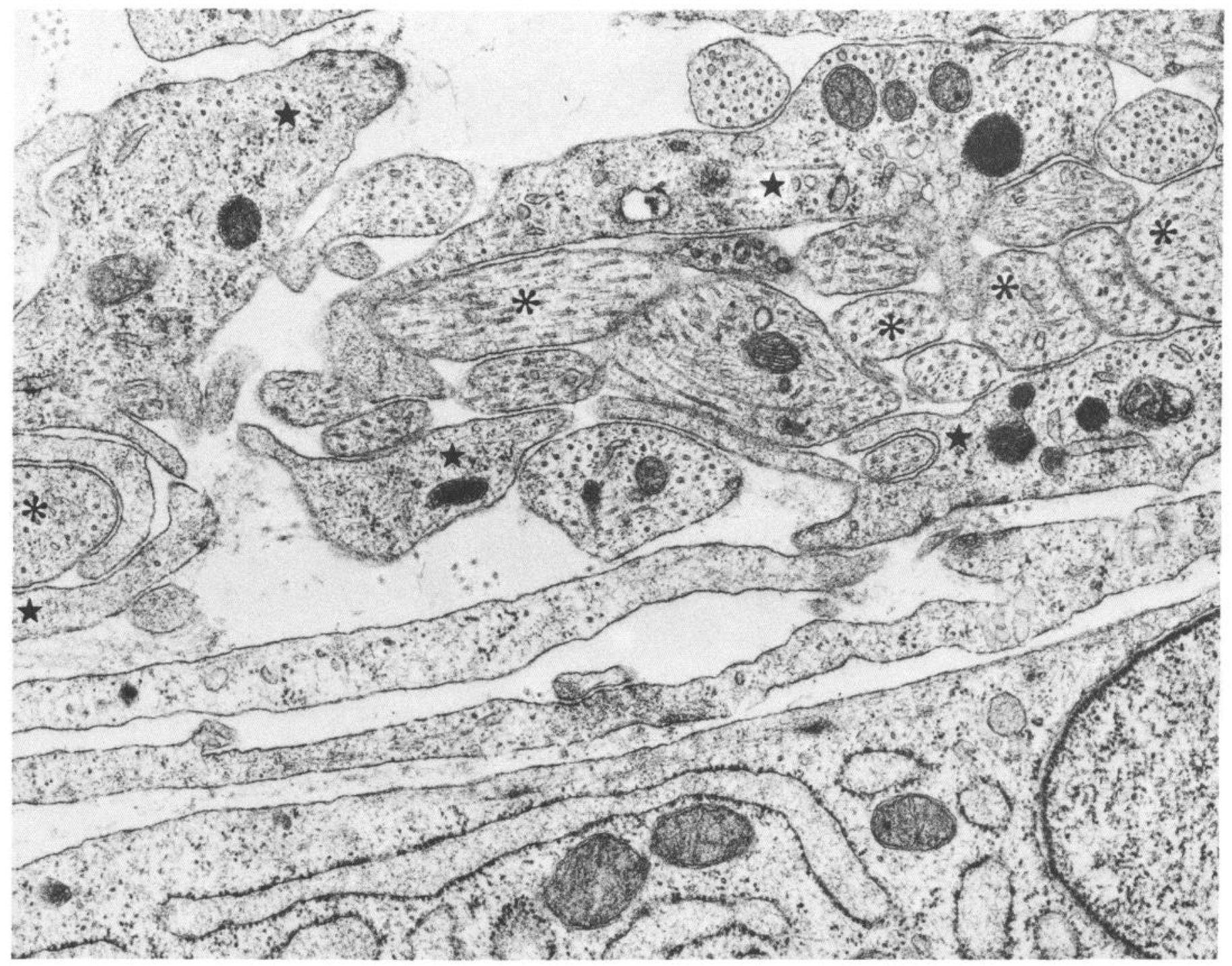

Figure 9. Outgrowth from E21 ganglion grown on air-dried collagen for $30 \mathrm{~d}$. Neurites (asterisks) remain largely unensheathed by SC cytoplasm (stars). In the absence of normal basal lamina formation, it is difficult to distinguish between neurites and SC processes unless granular endoplasmic reticulum cisterns or ribosomes are present. A few collagen fibrils have appeared. The substratum is below the fibroblast, shown in part at the bottom of the figure. $\times 32,000$.

Anti-laminin antibodies stained components of both E15 and E20 outgrowth (Fig. 5), but with different patterns. Anti-laminin antibodies stained NNCs in E1 5 cultures with a punctate pattern that delineated the boundaries of each cell (Fig. 5c). In E20 cultures the staining was denser and more complex. A scattered or linear punctate staining pattern was intermixed with a more diffuse staining (Fig. $5 f$ ). Thus, immunocytochemical staining also suggested that E15 outgrowth contained SCs, whereas E20 outgrowth contained both SCs and fibroblasts.

\section{Identification of SCs by functional assay}

In order to establish unequivocally that NNCs migrating out of E15 explants were functionally competent SCs, we tested their ability to ensheathe and form myelin in cultures containing sensory neurons free of their endogenous NNCs. Areas (approximately $2 \mathrm{~mm}^{2}$ ) of NNC-containing tissue from the outgrowth of an E15 SCG culture were cut out and transferred onto established cultures containing a pure population of dorsal root ganglion neurons, such that NNCs were in direct contact with neurites (Cornbrooks et al., 1983b) (Fig. 6a). The NNCs proliferated rapidly, and, $9 \mathrm{~d}$ after transplantation, segments of myelin were evident by light-microscopic observation (Fig. $6 b$ ) on either single- (ammoniated) or double-layered collagen. Further examination by electron microscopy revealed ensheathment of unmyelinated neurites and the formation of basal lamina and collagen fibrils, as well as normal-appearing myelin sheaths (Fig. 6c), thus confirming the identification of the cells as SCs. No fibroblast-like cells were seen in these cultures. Similar results were obtained when NNCs from E20 outgrowth were transplanted onto similar dorsal root ganglion cultures (data not shown). Because the results described thus far indicated that E15 outgrowth contained a pure population of SCs, whereas E20 outgrowth contained both SCs and fibroblasts, we next studied the NNCs in SCG outgrowth by electron microscopy.

\section{Electron-microscopic observations}

Electron-microscopic examination of E15 and E20 ganglion cultures after varying lengths of time confirmed the presence of one and two populations of NNCs, respectively. When these two cell populations were present (in E20 cultures), characteristics typical of both SCs and fibroblasts were observed (Figs. 7 and 9). Cells identified as fibroblasts were flattened and oriented 


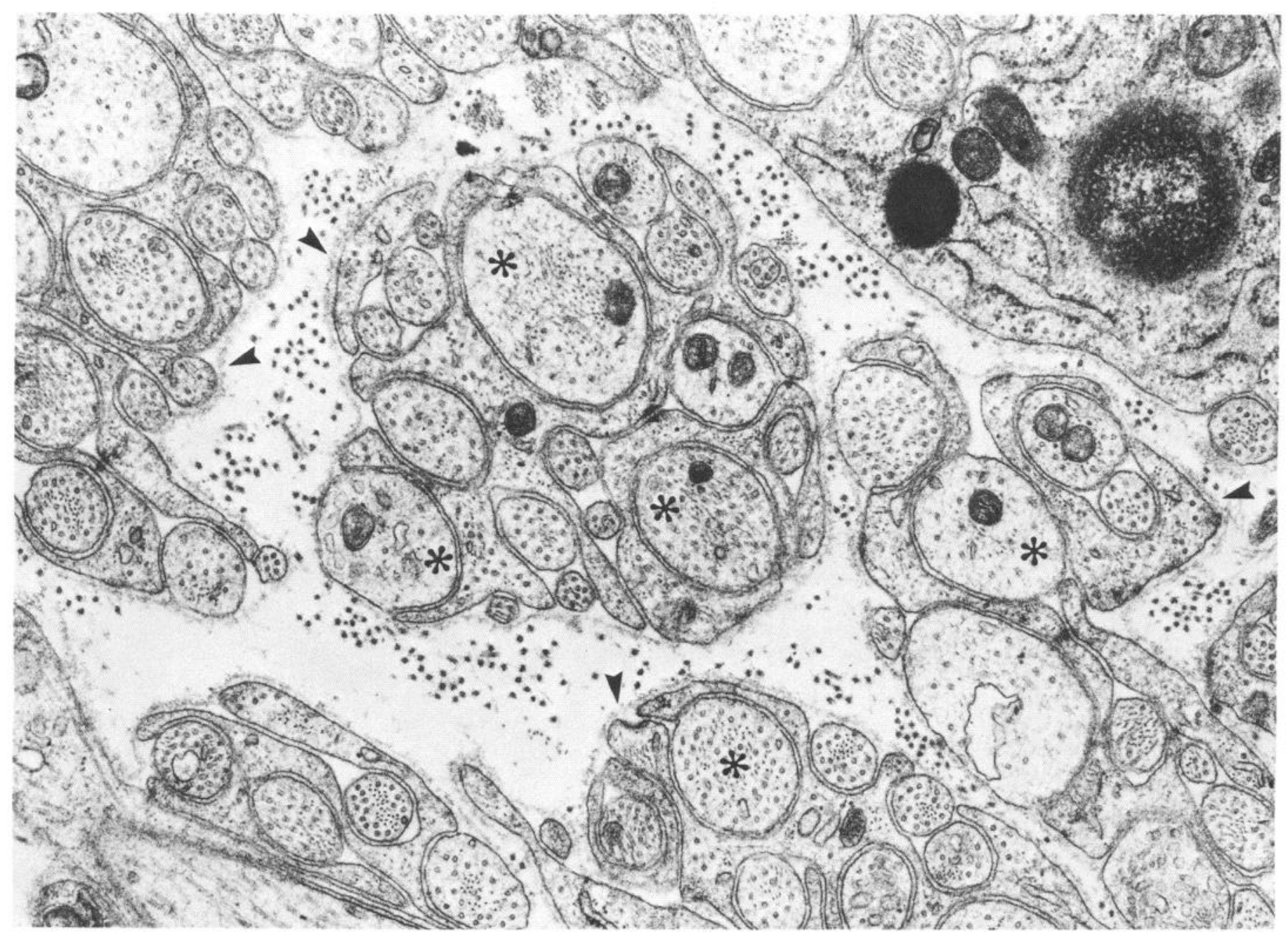

Figure 10. Outgrowth from E20 ganglion grown on double-layered collagen for $33 \mathrm{~d}$. This electron micrograph demonstrates that ensheathment of SCG neurites by SCG SCs in the presence of fibroblasts may be obtained under certain culture conditions. The medium was similar in serum and embryo extract content to that used for the other cultures illustrated in this paper. Along with this ensheathment, basal lamina (arrowheads) and collagen fibrils (typically situated parallel to the neurites) have been formed. $\times 32,000$.

in strata parallel to the culture dish surface. They exhibited prominent, often dilated granular endoplasmic reticulum cisterns that were usually oriented parallel to the culture dish surface (Fig. 7). Bundles of thin filaments were present and were, in some cases, observed to traverse the cytoplasm to enter a junctional specialization at the cell surface; these bundles thus appeared to correspond to stress fibers. Fibroblasts were occasionally attached to each other by junctions, and the involved parts of the cell were sometimes in a "ball-and-socket" configuration.

In E20 outgrowth, cells resembling SCs were perched on top of the cells just described after several days in vitro (Fig. 7) or were found with neurites primarily in one stratum among many layers of the fibroblast-like cells after longer periods in vitro. Schwann-type cells were always present in neurite-containing areas. Their cytoplasm was denser because of the greater abundance of unbound ribosomes, and their granular endoplasmic reticulum cisterns were more flattened and filled with denser product than the cells identified as fibroblasts. The cisterns were not necessarily oriented parallel to the culture dish surface (Fig. 7). Sheets of cytoplasm emanating from the Schwann-type cells approached or curved around neurites, in contrast to the fibroblast-like cells. Ball-and-socket configured attachment junctions were not noted. Both cell types occasionally exhibited a cilium and related basal body.

The single-cell population observed in E15 outgrowth resembled SCs. In $3 \mathrm{~d}$ cultures, the cytoplasm was composed chiefly of ribosomes; by $10 \mathrm{~d}$, greater numbers of other organelles were present. The "meandering" cytoplasmic sheets (Fig. 8) were particularly striking in a number of cultures, causing an SC to take on the configuration of an octopus. These processes, seen at all culture periods studied, approached or curved around neurites, but rarely typically ensheathed a neurite singly.

Compared to cultures containing sensory neurons, neither E15 nor E20 ganglion preparations exhibited the expected neurite ensheathment and extracellular matrix production, even after $30 \mathrm{~d}$ of culture. As illustrated in Fig. 9, SC processes provided a covering or compartments for bundles of neurites, but did not usually ensheathe neurites singly or in groups of two or three neurites. In addition, SCs exhibited little basal lamina on their surfaces; only an occasional patch of material was visible on the SC exterior in any age culture studied. Little additional extracellular matrix material was found in the $3,10,11$, or $20 \mathrm{~d}$ E15 or E20 cultures. In the $30 \mathrm{~d}$ E20 outgrowth, some collagen fibrils were identified (Fig. 9), but there were fewer than expected. Another abnormality in extracellular matrix produc- 
tion in the oldest culture studied ( $33 \mathrm{~d}$ ) was the formation of large aggregates of " $10 \mathrm{~nm}$ " fibrils resembling the microfibrils normally associated with elastin (not illustrated). Deficiencies in ensheathment and extracellular matrix formation were consistent in all the sympathetic cultures grown on undiluted or diluted air-dried collagen. The presence of fibroblasts (including the addition of skin fibroblasts to an E15 ganglion culture) did not foster normal development. The use of reduced amounts of serum and embryo extract ( 10 and $2 \%$, respectively) in the culture medium in these experiments is not considered to be the chief cause of these abnormalities. Using a different type of collagen substratum (see below), this medium allowed more normal differentiation of E20 cultures - as much as occurred in a more enriched medium containing $25 \%$ serum and $10 \%$ embryo extract.

Thus, the outgrowth of E15 and E20 ganglion cultures was seen to contain one- and two-cell populations, respectively, and the cellular characteristics corresponded to SCs and fibroblasts. Occasional cells could not be identified with certainty as either type, but the majority of cells observed fit into these categories. In most cultures, however, including those containing fibroblasts, typical ensheathment and extracellular matrix formation were not achieved, as reported above. In the present study, the only two instances in which normal SC differentiation was observed were (1) when E15 SCs were cultured with dorsal root ganglion neurons (see previous section and Fig. 6), on singlelayered ammoniated collagen or double-layered air-dried on ammoniated collagen, and (2) in a few cases when an E20 ganglion was cultured on a double-layered collagen substratum. The use of this double collagen layer (with either the more enriched medium or the medium utilized for this study) led to ensheathment of neurites, appearance of SC basal lamina, and formation of collagen fibrils in the SC-neurite domains (Fig. 10).

\section{Discussion}

The results from this study may be summarized as follows. (1) The cellular outgrowth from early E1 5 rat SCG explants consists of neurites and their accompanying SCs only; the lack of endogenous fibroblasts in a large percentage of the cultures eliminates the need for antimitotic agents. By simply removing the SCG explant, the location of the neuronal somata, a culture containing only SCs may be obtained. By briefly treating the neuron-SC cultures with an antimitotic agent, neuron-only cullures are obtained. Thus, this system can be used to generate neurons plus SCs and pure populations of SCs or neurons (from early E15 SCG) with no or minimal use of an antimitotic agent. (2) In contrast to E15 SCG cultures, the outgrowth from E20 SCG explants contains fibroblasts in addition to SCs. Our study suggests that, at embryonic stages E14-15, the predominant NNC type in the SCG is the SC and that fibroblasts begin to populate the ganglion subsequently. Culture of late E15 ganglia results in an increasing number of fibroblasts accompanying the SCs in the outgrowth. (3) In both E15 and E20 SCG outgrowth, littlc cnshcathment of neurites or production of extracellular matrix occurs when cultures are grown for as long as $30 \mathrm{~d}$ on a single layer of air-dried collagen. Ensheathment of neurites and production of extracellular matrix may be obtained, however, when E20 SCG are grown for a similar period on a modified (double-layered) collagen substratum. Also, SCs from SCG of both ages are able to ensheathe and myelinate dorsal root ganglion neurons and form basal lamina by $9 \mathrm{~d}$ in culture on singlelayered ammoniated or double-layered collagen.

In vitro studies of the NNCs of sympathetic ganglia are few (for a review, see Unsicker, 1983) and have employed, primarily, light microscopy. SCs described as bipolar, followed by fibroblast-like cells, were noted to migrate from adult human sympathetic ganglia cultured in a plasma clot and in a medium containing both chick embryo extract and human placental se- rum (Murray and Stout, 1942). In cultures of rat or mouse sympathetic ganglia grown under similar conditions, Ernyei and Young (1966) noted neurite investment by elongated SCs, which demonstrated rhythmic contractions, and occasionally a fibroblast-like cell. In cultures of rat, chick, or guinea pig sympathetic ganglia grown on a collagen substratum in serum-containing medium, Chamley et al. (1972) described a variety of cells, including SCs, satellite cells, fibroblasts, macrophages, and cells thought to resemble oligodendroglia and astrocytes. The SCs, described as bi- or tripolar, again exhibited pulsatile activity, as observed by time-lapse cinematography. In cultures of frog sympathetic ganglia grown on collagen in serum-containing medium, Hill and Burnstock (1975) observed a variety of NNCs, including satellite cells apposed to neuronal somata, spindleshaped and pulsatile SCs, epithelial cells of possible perineural origin (which were also contractile), fibroblasts, melanocytes, and macrophages. Included in this study was an electron micrograph showing two axons ensheathed by SCs within a basal lamina. In contrast, in cultures of chick sympathetic ganglia grown on glass, flattened mesenchymal cells formed an underlying cellular layer, but "glial" cells were few in number, particularly between neuronal somata (Hervonen, 1975). Several nerve fibers, however, were shown by electron microscopy to be wrapped in glial processes but, curiously, without apparent basal lamina. Our earlier rat SCG cultures were considered to contain SCs and fibroblasts (Johnson et al., 1980a, b), as well as satellite cells related to neuronal somata (Johnson and Bunge, 1983; Olson and Bunge, 1973); the morphology of NNCs in the SCG outgrowth was seen to vary depending on ganglionic age and substratum (Roufa et al., 1983). The present report is the first to use a variety of procedures, including immunocytochemical staining at the light-microscopic level and electron microscopy, to specifically identify the NNCs in SCG cultures.

The paucity of ensheathment of SCG neurites by SCs in both the E15 and E20 outgrowths when grown on air-dried collagen was unexpected because these SCG SCs were able to ensheathe and myelinate cultured dorsal root ganglion neurites. Several factors, particularly neuronal contact and SC secretion, are now known to affect SC proliferation and differentiation (reviewed in Bunge et al., 1983). Culture studies have shown that SC proliferation in the chick sympathetic system (McCarthy and Partlow, 1976) and the rat dorsal root ganglion (Wood and Bunge, 1975) is stimulated by contact with neurons and their proccsses. In a scrics of papers, Salzer and colleagues (Salzer and Bunge, 1980; Salzer et al., 1980a, b) demonstrated that a membrane fraction prepared from sensory ganglion neurites is mitogenic for SCs. Cassel et al. (1982) noted that the extent of $\mathrm{SC}$ proliferation in vitro, following the addition of an axolemmal-enriched membrane fraction, was affected by the type of culture substratum used. The percentage of labeled nuclei decreased 3.5-fold when SCs were grown on undiluted air-dried collagen instead of ammoniated collagen.

When neurons and SCs (both from dorsal root ganglia) are cultured in a defined medium lacking serum and embryo extract, SCs continue to proliferate, but they fail to differentiate; i.e., they neither ensheathe and myelinate neurites nor produce extracellular matrix structures, basal lamina and collagen fibrils (Moya et al., 1980). This lack of SC function is rapidly reversed by replacing the defined medium with complete (serum- and embryo extract-containing) medium. Ensheathment deficit and absence of formed extracellular matrix in defined medium are correlated with reduction in triple-helical collagenous products released by SCs (Bunge et al., 1983; Eldridge et al., 1984). When SCs are orphaned from neurons for 2 weeks, SCs release less type IV collagen (Carey et al., 1983) and newly formed basal lamina is not seen electron-microscopically (Bunge et al., 1982). When SC secretion is perturbed during expansion of the outgrowth, as mentioned above for defined medium or after the 
addition of cis-hydroxyproline to complete medium (Copio and Bunge, 1980), both the lack of deposited extracellular matrix and deficient ensheathment are consistently seen. These linked changes in SC function are also seen in dystrophic mouse root and nerve in vivo (Jaros and Bradley, 1978, 1979) and nerve in vitro (Okada et al., 1980). In the animal, where the more severely affected root regions can be identified, large bundled axons devoid of ensheathment are related to SCs that exhibit deficient basal lamina. The findings reported herein are consistent in that lack of ensheathment in the E15 and E20 SCG outgrowth is accompanied by an absence of basal lamina and collagen fibrils. When the substratum is modified, allowing better SC differentiation in some cultures, ensheathment improves and basal lamina and collagen fibrils become evident (Fig. 10).

But there appears to be a difference in the culture conditions required for $\mathrm{SC}$ differentiation among sensory ganglion neurons versus SCG neurons. SCs related to sensory neurons differentiate normally when given medium containing embryo extract and serum and, provided they contact both axons and the substratal surface, usually a single layer of collagen gelled by ammoniation (Bunge and Bunge, 1978). In the present work, SCs cultured with SCG neurons failed to ensheathe and form extracellular matrix components even though the medium contained both embryo extract and serum and the SCs contacted axons and a single layer of air-dried collagen. The SCs from SCG expressed normal function when cultured with sensory neurons, however, suggesting that the required conditions for SC differentiation are different in the presence of sympathetic neurons. In contrast to SCs among sensory neurons, SCs interacting with sympathetic neurons appear to be driven less by the neurons and to depend more on the influence of environmental conditions such as the collagen substratum. A few E20 SCG cultures in which ensheathment and basal lamina formation occurred were grown on double-layered collagen (air-dried on ammoniated), rather than on a single layer of air-dried collagen.

In this regard, it is interesting to note that $\mathrm{SC}$ function in vivo varies considerably in some areas of the PNS. In olfactory nerve, SCs provide communal ensheathment for groups of axons rather than ensheathing each neurite singly (Bunge, 1968; Rafols and Getchell, 1983). A most dramatic variation in ensheathment function occurs in the enteric plexus, where ensheathing cells provide an astrocyte-like ensheathment for axons (Jessen and Mirsky, 1983; Llewellyn-Smith et al., 1983). (Also, there is very little extracellular matrix present in this region of the nervous system.) These observations, taken together with our observations herein, suggest that both neuronal and environmental influences combine to determine the final state of SC expression in the body. In addition to the ensheathment and matrix formation differences, there is also the question raised in our work concerning the change in SC shape, from flattened in E15 cultures, to spindle-shaped in E20 cultures. The rat SCG culture system will offer an opportunity to further study the factors that influence SC differentiation and function.

\section{References}

Aguayo, A. J., and G. M. Bray (1984) Cell interactions studied in the peripheral nerves of experimental animals. In Peripheral Neuropathy, Vol. 1, 2nd Ed., P. J. Dyck, P. K. Thomas, E. H. Lambert, and R. P. Bunge, eds., pp. 360-377, Saunders, Philadelphia.

Brockes, J. P., K. L. Fields, and M. C. Raff (1979) Studies on cultured rat Schwann cells. I. Establishment of purified populations from cultures of peripheral nerve. Brain Res. 165: 105-118.

Bunge, M. B., A. K. Williams, and P. M. Wood (1982) Neuron-Schwann cell interaction in basal lamina formation. Dev. Biol. 92: 449-460.

Bunge, M. B., R. P. Bunge, D. J. Carey, C. J. Cornbrooks, C. F. Eldridge, A. K. Williams, and P. M. Wood (1983) Axonal and nonaxonal influences on Schwann cell development. In Tarbox Parkinson's Disease Symposium: Developing and Regenerating Vertebrate Nervous
Systems, P. W. Coates, R. R. Markwald, and A. D. Kenny, eds., pp. 71-105, Liss, New York.

Bunge, R. P. (1968) Glial cells and the central myelin sheath. Physiol. Rev. 48: 197-251.

Bunge, R. P., and M. B. Bunge (1978) Evidence that contact with connective tissue matrix is required for normal interaction between Schwann cells and nerve fibers. J. Cell Biol. 78: 943-950.

Bunge, R. P., and M. B. Bunge (1984) Tissue culture observations relating to peripheral nerve development, regeneration and disease. In Peripheral Neuropathy, Vol. 1, 2nd Ed., P. J. Dyck, P. K. Thomas, E. H. Lambert, and R. P. Bunge, eds., pp. 378-400, Saunders, Philadelphia.

Bunge, R. P., and P. Wood (1973) Studies on the transplantation of spinal cord tissue in the rat. I. The development of a culture system for hemisections of embryonic spinal cord. Brain Research 57: 261276.

Bunge, R. P., M. B. Bunge, and C. F. Eldridge (in press) Linkage between axonal ensheathment and basal lamina production by Schwann cells. Annu. Rev. Neurosci.

Carey, D. J., C. F. Eldridge, C. J. Cornbrooks, R. Timpl, and R. P. Bunge (1983) Biosynthesis of type IV collagen by cultured rat Schwann cells. J. Cell Biol. 97: 473-479.

Cassel, D., P. M. Wood, R. P. Bunge, and L. Glaser (1982) Mitogenicity of brain axolemma membranes and soluble factors for dorsal root ganglion Schwann cells. J. Cell. Biochem. 18: 433-445.

Chamley, J. H., G. E. Mark, and G. Burnstock (1972) Sympathetic ganglia in culture. II. Accessory cells. Z. Zellforsch. 135: 315-327.

Copio, D. S., and M. B. Bunge (1980) Use of a proline analog to disrupt collagen synthesis prevents normal Schwann cell differentiation. J. Cell Biol. 87: 114a.

Cornbrooks, C. J., D. J. Carey, J. A. McDonald, R. Timpl, and R. P. Bunge (1983a) In vivo and in vitro observations on laminin production by Schwann cells. Proc. Natl. Acad. Sci. USA 80: 3850-3854.

Cornbrooks, C. J., F. A. Mithen, M. Cochran, and R. P. Bunge (1983b) Factors affecting Schwann cell basal lamina formation in cultures of dorsal root ganglia from mice with muscular dystrophy. Dev. Brain Res. 6: 57-67.

Eldridge, C. F., M. B. Bunge, and R. P. Bunge (1984) The effects of ascorbic acid on Schwann cell basal lamina assembly and myelination. J. Cell Biol. 99: 404a.

Ernyei, S., and M. R. Young (1966) Pulsatile and myelin-forming activities of Schwann cells in vitro. J. Physiol. 183: 469-480.

Estridge, M. E., and R. P. Bunge (1978) Compositional analysis of growing axons from rat sympathetic neurons. J. Cell Biol. 79: 138155.

Hervonen, H. (1975) Differentiation of sympathetic sympathicoblasts in cultures of chick ganglia. Anat. Embryol. 146: 225-243.

Hill, C. E., and G. Burnstock (1975) Amphibian sympathetic ganglia in tissue culture. Cell Tissue Res. 162: 209-233.

Jaros, E., and W. C. Bradley (1978) Development of the amyelinated lesion in the ventral root of the dystrophic mouse. J. Neurol. Sci. 36 : 317-339.

Jaros, E., and W. G. Bradley (1979) Atypical axon-Schwann cell relationships in the common peroneal nerve of the dystrophic mouse: An ultrastructural study. Neuropathol. Appl. Neurobiol. 5: 133-147.

Jessen, K. R., and R. Mirsky (1983) Astrocyte-like glia in the peripheral nervous system: an immunohistochemical study of enteric glia. J. Neurosci. 3: 2206-2218.

Johnson, M. I., and R. P. Bunge (1983) Plasticity in neurotransmitter expression and the use of neuronal relays in spinal cord repair. In Spinal Cord Reconstruction, C. C. Kao, R. P. Bunge, and P. J. Reier, eds., pp. 329-340, Raven, New York.

Johnson, M. I., C. D. Ross, E. Meyers, L. Spitznagel, and R. P. Bunge (1980a) Morphological and biochemical studies on the development of cholinergic properties in cultured sympathetic neurons. I. J. Cell Biol. 84: 680-691.

Johnson, M. I., C. D. Ross, and R. P. Bunge (1980b) Morphological and biochemical studies on the development of cholinergic properties in cultured sympathetic neurons. II. Dependence on postnatal age. J. Cell Biol. 84: 692-704.

Llewellyn-Smith, I. J., J. B. Furness, A. J. Wilson, and M. Costa (1983) Organization and fine structure of enteric ganglia. In Autonomic Ganglia, L.-G. Elfvin, ed., pp. 145-182, Wiley, New York.

Manthorpe, M., S. Skaper, and S. Varon (1980) Purification of mouse 
Schwann cells using neurite-induced proliferation in serum-free monolayer culture. Brain Res. 196: 467-482.

McCarthy, K., and L. Partlow (1976) Neuronal stimulation of $\left[{ }^{3} \mathrm{H}\right]$ thymidine incorporation by primary cultures of highly purified nonneuronal cells. Brain Res. 114: 415-426.

Moya, F., R. P. Bunge, and M. B. Bunge (1980) Schwann cells proliferate but fail to differentiate in defined medium. Proc. Natl. Acad. Sci. USA 77: 6902-6906.

Murray, M. R., and A. P. Stout (1942) Characteristics of human Schwann cells in vitro. Anat. Rec. 84: 275-285.

Okada, E., R. P. Bunge, and M. B. Bunge (1980) Abnormalities expressed in long-term cultures of dorsal root ganglia from the dystrophic mouse. Brain Res. 194: 455-470.

Olson, M. I., and R. P. Bunge (1973) Anatomical observations on the specificity of synapse formation in tissue culture. Brain Res. 59: 1933.

Rafols, J. A., and T. V. Getchell (1983) Morphological relations between the receptor neurons, sustentacular cells and Schwann cells in the olfactory mucosa of the salamander. Anat. Rec. 206: 87-101.

Ratner, N., P. Wood, L. Glaser, and R. Bunge (in press) Further characterization of the neuronal cell surface protein mitogenic for Schwann cells. In Glial-Neuronal Communication in Development and Regeneration, H. Altause and W. Seisert, eds., Academic, London.

Roufa, D., C. Cornbrooks, M. Johnson, and M. Bungc (1982) Preparation of homogenous populations of immature Schwann cells from early embryonic sympathetic ganglia. Soc. Neurosci. Abstr. 8: 240.

Roufa, D. G., M. I. Johnson, and M. B. Bunge (1983) Influence of ganglion age, non-neuronal cells and substratum neurite outgrowth in culture. Dev. Biol. 99: 225-239.

Salzer, J. L., and R. P. Bunge (1980) Studies of Schwann cell proliferation. I. An analysis in tissue culture of proliferation during development, Wallerian degeneration and direct injury, J. Cell Biol. 84: $739-752$.

Salzer, J. L., R. P. Bunge, and L. Glaser (1980a) Studies of Schwann cell proliferation. III. Evidence for the surface localization of the neurite mitogen. J. Cell Biol. 84: 767-778.

Salzer, J. L., A. K. Williams, L. Glaser, and R. P. Bunge (1980b) Studies of Schwann cell proliferation. II. Characterization of the stimulation and specificity of the response to a neurite membrane fraction. J. Cell Biol. 84: 753-766.

Sanes, J. R. (1983) Roles of extracellular matrix in neural development. Annu. Rev. Physiol. 45: 581-600.

Unsicker, K. (1983) Cell and tissue culture studies in the sympathoadrenal system. In Autonomic Ganglia, L.-G. Elfvin, ed., pp. 475-505, Wiley, New York.

Varon, S., and R. P. Bunge (1978) Trophic mechanisms in the peripheral nervous system. Annu. Rev. Neurosci. 1: 327-361.

Webster, H. deF., and J. T. Favilla (1984) Development of peripheral nerve fibers. In Peripheral Neuropathy, Vol. 1, 2nd ed., P. J. Dyck, P. K. Thomas, E. H. Lambert, and R. P. Bunge, eds., pp. 329-359, Saunders, Philadelphia.

Wood, P. M. (1976) Separation of functional Schwann cells and neurons from normal peripheral nerve tissue. Brain Res. 115: 361-375.

Wood, P. M., and R. P. Bunge (1975) Evidence that sensory axons are mitogenic for Schwann cells, Nature 256: 662-664. 